\title{
Erratum to: Obstetricians' perspective towards cesarean section delivery based on professional level: experience from Egypt
}

Mohamed M. Shaaban • Waleed Ali Sayed Ahmed • Zeinab Khadr · Hesham F. El-Sayed

Published online: 30 August 2013

(C) Springer-Verlag Berlin Heidelberg 2013

Erratum to: Arch Gynecol Obstet (2012) 286:317-323

DOI 10.1007/s00404-012-2277-7

Unfortunately, the author's name was published incorrectly in the original publication. The correct name should read Waleed Ali Sayed Ahmed (W. A. Sayed Ahmed).

The online version of the original article can be found under doi:10.1007/s00404-012-2277-7.

M. M. Shaaban - W. A. Sayed Ahmed

Department of Obstetrics and Gynaecology,

Suez Canal University, Ismailia, Egypt

M. M. Shaaban ( $\square)$

10 Talaal Saadallah st, Haram Rd, Cairo, Egypt

e-mail: mohmsh20@hotmail.com

Z. Khadr

Department of Statistics, Faculty of Economics and Political Sciences and The Social Research Center,

The American University in Cairo, Cairo, Egypt

H. F. El-Sayed

Department of Pediatrics, Suez Canal University, Ismailia, Egypt 